\title{
Laparoscopic-assisted vaginal hysterectomy for endometrial cancer in high body mass index (BMI) patients: a report of six cases
}

\author{
H. Muppala • J. Rafi • S. K. Najia
}

Received: 10 June 2008 / Accepted: 1 August 2008 / Published online: 3 September 2008

(C) Springer-Verlag 2008

\begin{abstract}
In this case series, six women with high and very high body mass index (BMI; range, 30-65) underwent LAVH + bilateral salphingo-ophorectomy and removal of vaginal cuff under general anaesthesia for endometrial cancer. Initial Verres needle entry and insufflation was through the left upper quadrant at sub-coastal margin. With good surgical outcome, shorter hospitalisation and improved quality of life, we found that laparoscopic surgery was feasible in high and very high BMI patients with early stage endometrial cancer.
\end{abstract}

Keywords Endometrial cancer · High BMI · Laparoscopy · LAVH $\cdot$ Morbid obesity

\section{Introduction}

Endometrial cancer is the fifth most common cancer in women in the United Kingdom (UK) with around 6,430

Objective: The aim of the study was to evaluate the feasibility of laparoscopic-assisted vaginal hysterectomy in the management of early stage endometrial cancer in high and very high BMI patients.

Design: Prospective study, 2006-2007.

Setting: Royal Blackburn Hospital, Northwest England.

Main outcome measures: Success of LAVH, intra- and post-operative morbidity, and length of hospital stay.

H. Muppala $(\bowtie) \cdot$ S. K. Najia

Women's Health Directorate, Royal Blackburn Hospital,

Haslingden Road, Blackburn,

BB2 3HH Lancashire, UK

e-mail: drmuppala@dochdoc.com

J. Rafi

North Manchester General Hospital,

Manchester, UK cases diagnosed each year, which accounts for about $5 \%$ of all female cancers. There were 1,637 deaths from cancer in the UK in 2005 , accounting for only $2.2 \%$ of all female cancer deaths in the UK. Incidence of uterine cancer is rising in postmenopausal women, but 5-year survival rates have improved to more than $75 \%$ [1]. Obesity and nulliparity have long been recognised as risk factors for the development of uterine cancer.

Traditional approach for staging and treatment of the endometrial cancer is mainly by an exploratory laparotomy through midline incision with total abdominal hysterectomy and bilateral salphingo-oophorectomy (TAH+BSO), peritoneal washings and/or pelvic and para-aortic lymphadenectomy [2]. With the widespread usage and experience gained from laparoscopy, this has been extended as a treatment modality for patients affected by this cancer.

In our case series, believed to be one among few early studies in UK being undertaken, we looked at scenarios of women with high and very high BMI diagnosed with endometrial cancer undergoing $\mathrm{LAVH}+\mathrm{BSO}$ and removal of vaginal cuff under general anaesthesia (GA).

\section{Materials and methods}

Once suspected or diagnosed of uterine cancer, all patients were fast tracked through the system with 6-week rule for investigation and treatment. Management was based on local gynecological oncology network guidelines (Lancashire and South Cumbria cancer network). All patients had regular cervical screening with no abnormality, and none used hormone replacement therapy. They all had transabdominal and endo-vaginal scan followed by diagnostic hysteroscopy and endometrial biopsy (Tables 1 and 2). Cases 2 and 5 had magnetic resonance imaging (MRI) in 
Table 1 Summary of patient characteristics and histopathology reports

\begin{tabular}{|c|c|c|c|c|c|c|}
\hline Case no. & Age & BMI & Para & Presenting complaint and duration & Endometrial biopsy & Specimen report \\
\hline 1 & 68 & 64 & 3 & PMB, 2 months & Endometrioid adenocarcinoma grade 2 & Stage $1 \mathrm{~b}$, grade 2 \\
\hline 2 & 71 & 30 & 0 & PMB, 2 months & Endometrioid adenocarcinoma grade 2 & Stage $1 \mathrm{~b}$, grade 2 \\
\hline 3 & 74 & 40 & 0 & PMB, 3 weeks & Mild architectural atypia & Stage $1 \mathrm{~b}$, grade 2 \\
\hline 4 & 56 & 46 & 0 & PMB, 4 weeks & Complex endometrial hyperplasia & $\begin{array}{l}\text { Complex and atypical } \\
\text { endometrial hyperplasia }\end{array}$ \\
\hline 5 & 56 & 45 & 3 & PMB, 2 months & Adenocarcinoma of endometrium grade 2 & Stage $1 b$, grade 2 \\
\hline 6 & 50 & 34 & 2 & Menorrhagia, 12 months & $\begin{array}{l}\text { Complex atypical hyperplasia, } \\
\text { squamous metaplasia }\end{array}$ & $\begin{array}{l}\text { Stage 1a, grade } 1 \text { : in the } \\
\text { background of hyperplasia }\end{array}$ \\
\hline
\end{tabular}

$P M B$ postmenopausal bleeding

view of highly suspicious-looking endometrium on hysteroscopy. Our policy is to perform MRI in all patients where cancer is diagnosed. It is avoided in patients who cannot fit into the machine or claustrophobic. All patients had preoperative follow-up in a gynaecological outpatient clinic and anaesthetic review in view of co-morbid conditions (Table 3). Preoperative investigations include full blood count, liver and renal function tests and chest Xray were carried out. Patients were fully counselled about the advantages and disadvantages of laparoscopy, including risk of conversion to laparotomy.

They underwent $\mathrm{LAVH}+\mathrm{BSO}$ with removal of vaginal cuff under GA except case 4 who did not have removal of vaginal cuff. Patients with disseminated disease and previous multiple laparotomies, which increase the chance of visceral injuries by extensive intra-peritoneal adhesions, are contraindications. All cases were discussed in the multidisciplinary meeting both pre- and post-operatively. Not all patients required pelvic drain. Drain was placed only in those cases were postoperative bleeding is suspected. Patients were catheterised for $24 \mathrm{~h}$. Prophylactic intra- and post-operative antibiotics, and post-operative thrombo-prophylaxis were given as in-patients. Vagina was packed with antiseptic ribbon gauge. Rectus sheath from the 10-mm port sites were closed with the help of Jshaped needle. Drain and pack were removed on the following morning. All women checked for post-operative haemoglobin on day 2. Routine 6-week outpatient followup were arranged for clinical examination. Subsequent follow-ups will be three monthly for the first year, four monthly for the second year and then six monthly for next 3 years before being discharged.

In all the cases, same surgeon (with a special interest in laparoscopy in high BMI patients) performed the operation with the help of two assistants. Patients were placed in lithotomic position. Initial entry with Verres needle for $\mathrm{CO}_{2}$ insufflation was performed through the left upper quadrant, at the height of the dome of the lower margin of the left sub-coastal region. Verres needle is passed perpendicularly by the margin of the sub-coastal region with an initial pressure of $25 \mathrm{mmHg}$; as it traverses the abdominal layers, the pressure increases to $50 \mathrm{mmHg}$, and once it breaches the peritoneal layer, the pressure immediately drops to $<9 \mathrm{mmHg}$ high/free flow of the gas [3].

Table 2 Investigations performed

\begin{tabular}{|c|c|c|c|}
\hline $\begin{array}{l}\text { Case } \\
\text { no. }\end{array}$ & Pelvic and abdominal scan & Hysteroscopy & MRI \\
\hline 1 & $\mathrm{ET}=12.9 \mathrm{~mm}$ & $\begin{array}{l}\text { Thickened endometrium, irregular appearance and two } \\
\text { small polyps }\end{array}$ & \\
\hline 2 & $\mathrm{ET}=21 \mathrm{~mm}$, irregular endometrium & Enlarged cavity with suspicious-looking growth & Bulky uterus, enlarged cavity \\
\hline 3 & $\mathrm{ET}=31 \mathrm{~mm}$ containing cystic areas & Enlarged cavity with irregular endometrial lining & \\
\hline 4 & $\mathrm{ET}=3.7 \mathrm{~mm}$ and polyps & Enlarged cavity and multiple small polyps & \\
\hline 5 & $\mathrm{ET}=11 \mathrm{~mm}$ & $\begin{array}{l}\text { Thickened highly vascular endometrium } \\
\text { and two small polyps }\end{array}$ & $\begin{array}{l}\text { Endometrium of intermediate to } \\
\text { high signal occupying the whole } \\
\text { of the cavity extending into both } \\
\text { cornua }\end{array}$ \\
\hline 6 & $\begin{array}{l}\text { Enlarged fibroid uterus, } 125 \times 67 \times 81 \mathrm{~mm} \text {, } \\
\text { ET }=12.9 \mathrm{~mm}\end{array}$ & $\begin{array}{l}\text { Multiple small polyps and } \\
\text { hyperplastic endometrium }\end{array}$ & \\
\hline
\end{tabular}

MRI magnetic resonance imaging, ET endometrial thickness 
Table 3 Co-morbidity status and post-operative data

\begin{tabular}{llll}
\hline Case no. & Co-morbid medical conditions & Post-op analgesia & Day of discharge \\
\hline 1 & Hypertension, para-umbilical hernia, asthma, osteoarthritis & Patient-controlled epidural analgesia \\
2 & Hypercholesterolemia & Paracetamol, diclofenac & Paracetamol, diclofenac \\
3 & $\begin{array}{c}\text { Hypertension, type II DM, vertibasilar insufficiency, } \\
\text { ishaemic heart disease, hypercholesterolemia }\end{array}$ & 3 \\
4 & $\begin{array}{l}\text { Hypertension, hyperlipidemia, osteoarthritis, Meniere's } \\
\text { disease, irritable bowel syndrome, varicose veins }\end{array}$ & Paracetamol, diclofenac \\
5 & Hypertension, osteoarthritis & Patient-controlled IV morphine \\
& Hypertension, iron deficiency anaemia & analgesia, paracetamol, diclofenac \\
6 & & $\begin{array}{c}\text { Patient-controlled IV morphine analgesia, } \\
\text { paracetamol, diclofenac }\end{array}$ & 3 \\
\hline
\end{tabular}

After successful pneumoperitoneum, the first $10-\mathrm{mm}$ port is placed in the left upper quadrant. Subsequently, three more ports (one $10 \mathrm{~mm}$ and two $5 \mathrm{~mm}$ ) are placed under vision. Case two had five port entries. For improved access to pelvic cavity, we routinely used preoperative bowel preparation and, intra-operatively, endo-retractor for bowels. Short period of Trendelenberg's position were used until the upper pedicles were secured. Coagulation and cutting of the salphinges were undertaken, along with the opening of the anterior leaf of the broad ligament. Gas let out, leaving all the cannulas and camera in place for later checking of haemostasis. The rest of the procedure was carried out vaginally. Uterine pedicles were secured from below.

\section{Results}

See the summary of information in the following Tables 1, 2 and 3.

\section{Discussion}

The use of laparoscopy in cervical, endometrial and ovarian cancers has significantly improved over the last 15 years. Laparoscopic surgery for women with endometrial carcinoma was first reported by Childers and Surwit in 1991 and considered high BMI as exclusion criteria for laparoscopic staging [4]. Over the years, the experience gained with improved instrumentation and techniques; laparoscopic procedures have been generally regarded as safe and feasible in women with high BMI patients [5-7]. Stages $1 \mathrm{a}-\mathrm{c}$ and $2 \mathrm{a}$ and $\mathrm{b}$ are managed by LAVH+BSO and removal of vaginal cuff $+/-$ pelvic aortic node sampling. As per protocol advanced stages 1c and stage 2, high-grade or aggressive variants such as papillary serous or clear cell will have pelvic aortic lymph node sampling for surgical staging.
In our case series, neither procedural nor anaestheticrelated complications were encountered. However, other investigators [8] have reported abdominal wall haematomas and operative blood loss requiring blood transfusion, cuff cellulites and ileus requiring readmissions, intra-abdominal and pelvic abscesses, small bowel obstruction secondary to herniation through a 5-mm port site and septic thrombophlebitis. In view of these risk factors, we routinely gave prophylactic intra- and post-operative antibiotics for two successive days. In addition, a closed suction drain is placed into the pelvic cavity at the end of the vaginal procedure. In a prospective study involving 40 patients, conversion to laparotomy was seen in $7.5 \%$ cases with women of BMI greater than 28, but the morbidity and length of hospitalization were compared to women with low BMIs [9]. Other complications reported are small bowel obstruction secondary to herniation through laparoscopic 10-mm trocar sites, rarely through 5-mm trocar sites, cystotomy, ureteral transection, bleeding from the inferior epigastric vessels and pneumothorax [9].

No statistically significant differences in recurrence and survival rates have been noticed in short-term follow-up and have led to recommendation of laparoscopic procedures as a routine treatment option for endometrial cancer [10-13]. In a recent retrospective study involving 169 patients, the recurrence rate in the LAVH group was $8.7 \%$, compared with $16 \%$ in the laparotomy group. In the same study, overall survival and disease-free survival for the LAVH were 93\% and $91 \%$, compared with $86 \%$ and $84 \%$ in the TAH, respectively (insignificant) [14]. In another recent retrospective study involving 273 patients, the surgical technique of an open or closed vaginal cuff during open or laparoscopic surgery for endometrial cancer showed no significant impact on the local recurrence rate [15]. Following 8 months follow-up, none of our six patients have had any complications.

The only drawback reported is longer operating time [10, 16, 17]. The operating time in all the patients was within $2 \mathrm{~h}$, 
except case 1 where it was $4 \mathrm{~h}$ in view of laparoscopic repair of umbilical hernia. Cases 2, 4 and 6 underwent additional operations of laparoscopic adhesiolysis. All our patients recuperated uneventfully from the operation, and the mean duration of hospital stay was 4 days (Table 3 ). None of them required blood transfusion, as the maximum drop of haemoglobin was two in case 2, indicating less intraoperative blood loss. Most women had simple analgesia for postoperative pain, paracetamol and diclofenac. Case 1 had patient-controlled epidural analgesia for 3 days; cases 5 and 6 had patient-controlled IV morphine for 1 day (Table 2). None of the patients required night sedation.

In a prospective study involving 86 non-selective patients, Eltabbakh et al. concluded that the majority of women with early stage endometrial carcinoma could be treated with laparoscopy with an excellent surgical outcome, shorter hospitalisation, earlier recovery and improved quality of life [8]. Similar findings were reported by others in non-selective patients $[10,14,18-$ 20]. In one retrospective review of 90 patients, laparoscopic staging appeared to be a feasible alternative to traditional abdominal surgery for stage I and stage II disease, including no difference in disease recurrence in both of the groups [21].

From the patients' point of view, there is less risk of wound infection, haematomas, pneumonia, major bleeding as well as decreased chances of deep venous thrombosis from early ambulation. In consequence, there will be shorter hospital stay, less chances of hospital-acquired infection especially methicillin-resistant Staphylococcus aureus and early return to full normal activity. This also means reduced overall costs and improved efficiency of hospitals from increased turnover of beds. Other investigators too noted lower hospital costs in patients undergoing laparoscopic staging $[10,22]$.

In conclusion, the small incisions required for laparoscopic surgery and the absence of bowel manipulation decrease postoperative pain and ileus, and allowed for early ambulation and discharge. Our experience shows that they resumed full normal activity earlier (within 2 weeks) compared to having total abdominal hysterectomy. These patients were significantly more satisfied from the good outcome of the laparoscopic surgery as avoidance of large abdominal incisions. It has been proven beyond doubt that wound infection following laparotomy in obese women poses significant morbidity. Patient motivation and multidisciplinary involvement are crucial for the good outcome in women with very high BMI patients. For above-mentioned reasons, we underscore the safety and feasibility of the laparoscopic surgery in high and very high BMI patients with early stage endometrial cancer. However, larger studies are required to draw final conclusions.

\section{References}

1. Cancer Research UK. http://info.cancerresearchuk.org/cancerstats/ types/uterus/. Accessed September 2007

2. Volpi E, Ferrero A, Jacomuzzi ME, Carus AP, Fuso L, Martra F, Sismondi P (2006) Laparoscopic treatment of endometrial cancer: feasibility and results. Eur J Obstet Gynaecol Reprod Bio 124:232-236

3. Muppala H, Rafi J, Najia SK (2008) Laparoscopic insufflation through a defined surgical point in the left upper quadrant: a three year experience. Gynecol Surg (in press). doi:10.1007/s10397008-0397-7

4. Childers J, Surwit E (1991) A combined laparoscopic vaginal approach in the management of stage 1 endometrial cancer. Gynecol Oncol 45:46-51

5. Eltabbakh GH, Piver MS, Hempling RE, Recio FO (1999) Laparoscopic surgery in obese women. Obstet Gynecol 94:704708

6. Pasic R, Levine RL, Wolf Jr WM (1999) Laparoscopy in morbidly obese patients. J Am Assoc Gynecol Laparosc 6(3):307-312

7. Heinberg EM, Crawford BL III, Weitzen SH, Bonilla DJ (2004) Total laparoscopic hysterectomy in obese versus nonobese patients. Obstet Gynecol 103(4):674-680

8. Eltabbakh GH, Shamonki MI, Moody JM, Garafano LL (2001) Laparoscopy as the primary modality for the treatment of women with endometrial carcinoma. Cancer 91:378-387

9. Eltabbakh GH, Shamonki MI, Moody JM, Garafano LL (2000) Hysterectomy for obese women with endometrial cancer: laparoscopy or laparotomy? Gynecol Oncol 78(3):329-335

10. Gemignani ML, Curtin JP, Zelmanovich J, Patel DA, Venkataramana E, Barakat RR (1999) Laparoscopic assisted vaginal hysterectomy for endometrial cancer: clinical outcomes and hospital charges. Gynecol Oncol 73(1):5-11

11. Malur S, Possover M, Michels W, Schneider A (2001) Laparoscopic assisted vaginal versus abdominal surgery in patients with endometrial cancer-a prospective randomised trial. Gynecol Oncol 80:239-244

12. Obermair A, Manolitas TP, Leung Y, hammound IG, McCartney AJ (2004) Total laparoscopic hysterectomy for endometrial cancer: patterns of recurrence and survival. Gynecol Oncol 92:789-793

13. Tozzi R, Malur S, Koehler C, Schneider A (2005) Laparoscopy versus laparotomy in endometrial cancer: first analysis of survival of a randomised prospective study. Journal of Minimally Invasive Gynecology 12:130-136

14. Kalogiannidis I, Lambrechts S, Amant F, Neven P, Van Gorp T, Vergote I (2007) Laparoscopic assisted vaginal hysterectomy in clinical stage 1 endometrial cancer: safety, recurrence and long-term outcome. Am J Obstet Gynecol 196(3):248.e1-248. e8

15. Kohlberger P, Nowotny G, Speiser P, Joura E, Sliutz G, hefler L, Reinthaller A (2007) Surgical treatment of endometrial cancer: closure or non closure of the vagina affect the local recurrence rate? Anticancer Res 27(3B):1589-1591

16. Scribner DR Jr, Mannel RS, Walker JL, Johnson GA (1999) Cost analysis of laparoscopy versus laparotomy for early endometrial cancer. Gynecol Oncol 75:460-463

17. Fram KM (2002) Laparoscopically assisted vaginal hysterectomy versus abdominal hysterectomy in stage I endometrial cancer. Int J Gynecol Cancer 12:57-61

18. Liauw L, Chung YN, Tsoi CW, Pang CP, Cheung KB (2003) Laparoscopy for the treatment of women with endometrial cancer. Hong Kong Med J 9(2):108-112

19. Frigerio L, Gallo A, Ghezzi F, Trezzi G, Lussana M, Franchi M (2006) Laparoscopic assisted vaginal hysterectomy versus ab- 
dominal hysterectomy in endometrial cancer. Int $\mathrm{J}$ Gynaecol Obstet 93(3):209-213

20. Tollund L, Hansen B, Kier JJ (2006) Laparoscopic assisted vaginal versus abdominal surgery in patients with endometrial cancer stage 1. Acta Obstet Gynecol Scand 85(9):1138-1141

21. Zapico A, Fuentes P, Grassa A, Arnanz F, Otazua J, Cortes-Prieto J (2005) Laparoscopic assisted vaginal hysterectomy versus abdominal hysterectomy in stage I and II endometrial cancer: operating data, follow up and survival. Gynecol Oncol 98(2): 222-227

22. Spirtos NM, Schlaerth JB, Gross GM, Spirtos TW, Schlareth AC, Ballon SC (1996) Cost and quality of life analysis of surgery for early endometrial cancer: laparotomy versus laparoscopy. Am J Obstet Gynecol 174:1795-1800 